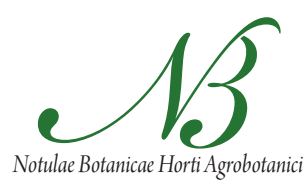

Cluj-Napoca

\title{
Univariate and Multivariate Analysis of Agronomical Traits of Preselected Argan Trees
}

\author{
Naïma AIT AABD*, Fouad MSANDA, Abdelhamid EL MOUSADIK \\ Laboratory of Biotechnology and Valorization of Natural Resources, Department of Biology, Faculty of Science, Ibn \\ Zohr University, CP 8106, Agadir80000, Morocco; aitaabdnaima@gmail.com (*corresponding author)
}

\begin{abstract}
A collection of thirty argan trees (Argania spinosa (L.) Skeels), representing the Aoulouz provenance in southwest of Morocco were used to study genetic variability and selection for three years. In this study, the genetic diversity of thirty genotypes (tree mothers) of $\operatorname{argan}$ (Argania spinosa) collected from Aoulouz was evaluated using agro-morphological characters. The main objective of the study was to assess and describe with multivariate analysis the genetic diversity in order to select good candidate trees for a future breeding program. The results obtained showed a large variation for all the traits examined. Analysis of variance using general linear model provided a significant variation between genotypes. Furthermore, genotypic and phenotypic variances for quantitative traits, particularly for seed length, seed width, almond length and oil content were higher. Phenotypic coefficient of variation was higher than genotypic coefficient of variation for all the characters. High heritability was recorded for oil content (97.90\%), seed width (72.68\%) and seed length (57.55\%) respectively, indicating the additive gene action. In addition, a three dimensional plot based on principal coordinate analysis method was used to evaluate the performance genotypes as to the production of oil for three years. The genotypes 'Ao- $12 \mathrm{R}$ ', 'Ao- $7 \mathrm{R}$ ', 'Ao- $4 \mathrm{R}$ ', 'Ao- $4 \mathrm{~V}$ ', 'Ao-11R', 'Ao-8V' and 'Ao-7V' were found to be the best for high oil content. Identification and selection with superior agronomic traits may be an effective method for genetic improvement of argan trees, and a first step for further breeding studies.
\end{abstract}

Keywords: Argania spinosa, genotype, heritability, oil content, selection

\section{Introduction}

Argan (Argania spinosa L. Skeels, Fam. Sapotaceae) is one of the most important oil seed plants in the world. It is native to Morocco, where is naturally distributed mainly in arid and sub arid of Southern - West areas. Due to their useful products (i.e., wood collection, grazing, oil), argan tree is one of the most economically and socially important tree species for the local population (Lybbert et al., 2011). It is a long-lived tree, growing widely under different architecture forms. The seed of mature tree is a source of excellent vegetable oil. This oil is very stable due to the high percentage of polyunsaturated fatty acids. Several studies of lipid composition of argan seeds have been published (Charrouf and Guillaume, 1999, 2002; Gharby et al., 2011; Nerd et al., 1994). Furthermore, it is one of the most expensive oils in the world markets, used for food, pharmaceutical and cosmetic industries (Lybbert et al., 2011). Moreover, drought stress, high exploitation and strong demand of oil contribute to the degradation, yield reduction and regression of surfaces of argan trees (Nouaim et al., 2007). Degradation of the argan trees is a serious problem for the south west of Morocco and it becomes necessary to develop conservation programs. Tree improvement is a stepwise process involving exploration, collection, evaluation, breeding, multiplication, distribution and conservation of genetic resources (Mishra, 2009). In the aim to meet the requirement of massive exploitation of oil argan, evaluation of good yielding argan tree is directly needed to select highly productive individuals. The selection is the most important activity in all tree breeding programs (Zobel and Tolbert, 1984), and variability is a key factor for selection programs. Therefore, it is necessary to detect the existing variation between the genotypes. So, in parallel with this approach, a guide to the genetic selection is examining the tree-to-tree variability in a number of relevant traits and identifying elite trees (White et al., 2007). Thus, several studies have examined the potential of argan by estimating genetic variability in different sites of argan tree (Ait Aabd et al., 2011; Bani Aameur and Ferradous 2001; Nouaim et al., 2007; Zunzunegui et al., 2010). The genetic variation for the trait under selection and a higher heritability are necessary to have response to selection (Falconer and Mackay, 1996; Maniee et al., 2009; Silva et al., 2009; Volker et al., 2008), and are strategic parameters for genetic improvement. Hence, genotype-environment or genotype-year interactions are important to decide a possible breeding method to improve cultivars with adequate adaptation to environments (Fox et al., 1997; Jenni and Hayes, 2010). However, such genetic gain from multi-trait selection depends upon the level of additive genetic variability in each trait, the selection intensity and the genetic correlations among traits (Falconer and Mackay, 1996). 
A number of studies have been initiated to assess variation in fruits, nuts and kernels of some important indigenous African tree species such as Adansonia digitata (Assogbadjo et al., 2006; Sanchez et al., 2011), Tamarindus indica (Fandohan et al., 2011), Balanites aegyptiaca (Abasse et al., 2011), Irvingia gabonensis (Leakey et al., 2000) and Sclerocarya birrea subsp. caffra (Gouwakinnou et al., 2011; Leakey et al., 2005:). Most of these studies have documented a continuous variation between and within studied populations for the investigated traits and have highlighted the possible ability to derive improved cultivars from the wild populations for the purposes of domestication (Sanchez et al., 2011). Besides, the first step in the plus tree selection is to state the selection criteria. So, previous studies carried out in oleaginous plant have found correlations among some fruits, seed traits related to the oil content and other factors such as moisture and soil nutrient (Iqbal et al., 2009; Kaushik et al., 2007a; Nehdi et al., 2012; Rao et al., 2008; Yadav et al., 2011) and several studies have been done on selection for high oil yield (Divakara et al., 2010; Kaushik et al., 2007b; Mishra, 2009). The aim of this study was to evaluate levels of genetic diversity in thirty argan trees of Aoulouz region, and to evaluate agronomic and morphological traits for a future breeding program. In this way, it might be possible to select the genotypes that show the most interesting characteristics and a quality product.

\section{Materials and methods}

\section{Study area}

Field expeditions were carried out in summer 2008, 2009 and 2010 in Aoulouz region (Province of Taroudant). The sampling site is located approximately at latitude $30^{\circ} 43^{\prime} \mathrm{N}$, longitude $08^{\circ} 09^{\prime} \mathrm{E}$ and at an altitude of $730-850 \mathrm{~m}$. The site features a semi-continental climate.
Annual precipitation is very irregular and ranges from 123 to $587 \mathrm{~mm}$, whilst the mean annual temperature is around $21^{\circ} \mathrm{C}$. Thirty trees were selected and geographical data including altitude, latitude and longitude were recorded for each tree, using a GPS device and projected on map after transformation using Global Mapper V.13 (Fig. 1). For each tree, 90 mature fruits were randomly collected and evaluated to select the superior genotypes.

\section{Morphological characterization}

Each year, ten morphological traits related to fruit, seed and almond were recorded for each tree. The measured characters were: fruit weight $(\mathrm{g})$, seed weight $(\mathrm{g})$, seed length $(\mathrm{mm})$, seed width $(\mathrm{mm})$, carpel number, almond number, almond weight $(\mathrm{g})$, almond length $(\mathrm{mm})$, almond width ( $\mathrm{mm}$ ) and oil content (\%). The oil content was estimated by Soxhlet method; it was determined using the formula given by Khalil and Manan (1990).

\section{Statistical analysis}

After evaluation of the investigated characters, an analysis of variance was performed using general linear model procedure of the software package Statistica V.6. Both univariate and multivariate analyses were performed on the data. The means were subjected to further statistical and genetically analysis. All statistical parameters: mean, range over years, variance and coefficient of variation were analyzed.

The mean square was used to estimate genetic variability parameters for the studied traits. Phenotypic and genotypic variance, phenotypic coefficient of variation $(\mathrm{PCV})$ and genotypic coefficient of variation (GCV), heritability in broad sense, genetic advance as percent of mean, were worked out for fruit, seed, almond traits and oil content as suggested by Lush (1940), Johnson et al. (1955) and Toker (1998).

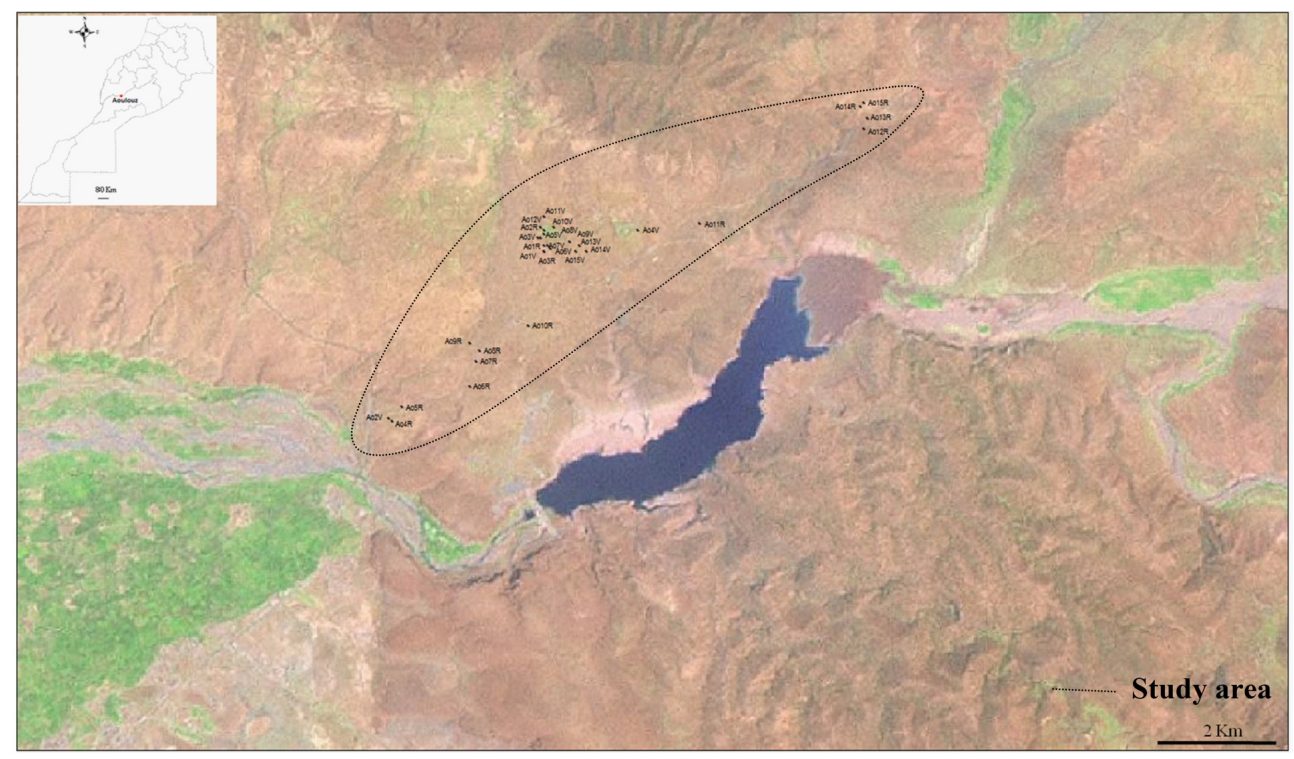

Fig. 1. Geographical distribution of the thirty trees selected in Aoulouz provenance 
310

The repeatability was estimated for observations both within and among individuals using the formula given by Falconer and Mackay (1996).

The data matrix was then prepared to be used in the subsequent multivariate analyses and genetic divergence analysis. The selection of number of performing genotypes for three years (2008-2010) was based on the criterion of oil content using the three dimensional plot based on principal coordinate analysis. Grouping of genotypes into different clusters was carried out following Tocher's procedure (Rao, 1952), and principal component analysis was done according to Rao (1964). The intra and inter-cluster distance and the relative contribution of different characters towards total divergence was calculated using the formula given by Singh and Choudhary (1977). Average intra-cluster $\mathrm{D}^{2}=\Sigma \mathrm{D}^{2} \mathrm{i} / \mathrm{n}$, where, $\Sigma \mathrm{D}^{2} \mathrm{i}=$ Sum of distances between all possible combination ( $\mathrm{n}$ ) of the varieties/ lines included in a cluster, $\mathrm{n}=$ all possible combinations (Rahman and Al Munsur, 2009).

\section{Results}

\section{Morphological analysis}

Mean values of the studied morphological characters, tested each year (2008 to 2010) showed considerable variations between genotypes for fruits, seeds and almonds characters studied (Tab. 1, Fig. 2). All the genotypes displayed considerable differences in their mean performance. The maximum weight of fruit $(5.61 \mathrm{~g})$ and seed $(3.38 \mathrm{~g})$ were observed in 'Ao-10R', and the minimum value was re-
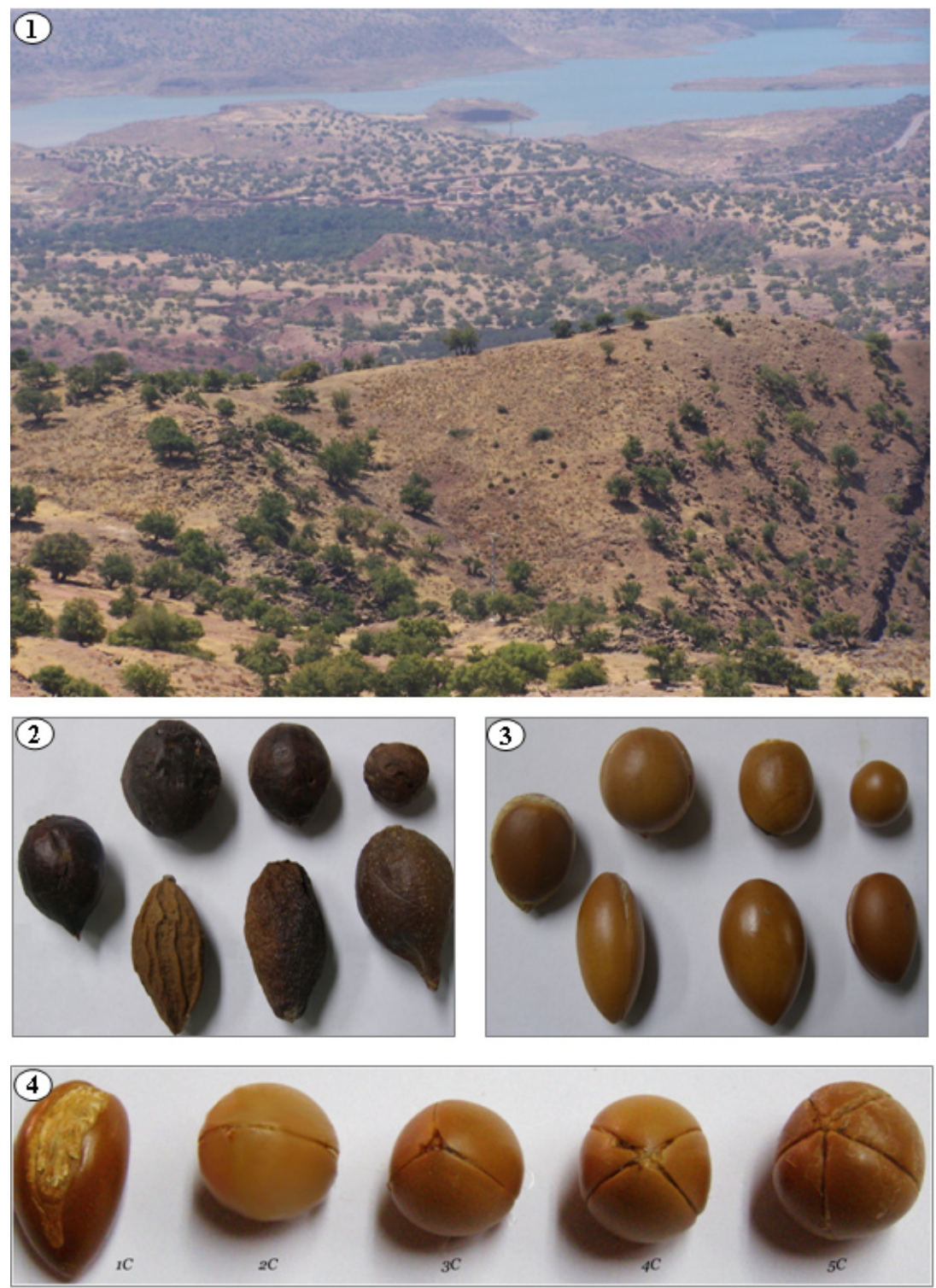

Fig. 2. Habitat and morphological variability of fruits and seeds of Argania spinosa: (1) naturally growing trees, (2), (3) fruits and seeds of argan tree with distinct morphological variations (results from 5 populations of Morocco), (4) number of carpels per seed $(1 \mathrm{C} ; 2 \mathrm{C} ; 3 \mathrm{C} ; 4 \mathrm{C} ; 5 \mathrm{C})$ 
Tab. 1. Mean values for various characters studied of different genotypes over three years

\begin{tabular}{|c|c|c|c|c|c|c|c|c|c|c|}
\hline \multirow{2}{*}{ Arbre $N^{\circ}$} & \multirow{2}{*}{$\begin{array}{c}\text { Fruit trait } \\
\text { FW }\end{array}$} & \multicolumn{4}{|c|}{ Seed trait } & \multicolumn{4}{|c|}{ Almond trait } & \multirow{2}{*}{ Oil content } \\
\hline & & SW & SL & SWi & $\mathrm{CN}$ & $\mathrm{AN}$ & AW & $\mathrm{AL}$ & AWi & \\
\hline 'Ao-1V' & 2.95 & 1.62 & 19.04 & 12.08 & 2.49 & 1.14 & 0.20 & 15.09 & 7.62 & 52.70 \\
\hline 'Ao-2V' & 3.56 & 2.01 & 20.83 & 12.92 & 2.20 & 1.04 & 0.23 & 18.81 & 8.78 & 51.17 \\
\hline 'Ao-3V' & 3.24 & 1.87 & 25.89 & 12.46 & 2.11 & 1.08 & 0.28 & 20.36 & 8.09 & 53.13 \\
\hline 'Ao- $4 \mathrm{~V}$ ' & 3.21 & 2.00 & 20.31 & 13.68 & 2.46 & 1.15 & 0.23 & 17.19 & 8.83 & 55.03 \\
\hline 'Ao-5V' & 4.91 & 2.85 & 22.07 & 15.26 & 2.12 & 1.25 & 0.31 & 18.99 & 9.80 & 52.97 \\
\hline Ao- $6 \mathrm{~V}$ & 3.52 & 2.09 & 20.51 & 13.26 & 2.05 & 1.21 & 0.28 & 16.17 & 8.34 & 52.68 \\
\hline 'Ao-7V' & 3.95 & 2.21 & 21.72 & 13.35 & 2.43 & 1.13 & 0.26 & 17.33 & 8.33 & 53.92 \\
\hline 'Ao-8V' & 3.15 & 1.82 & 18.94 & 13.14 & 2.12 & 1.18 & 0.24 & 15.55 & 8.55 & 54.72 \\
\hline 'Ao-9V' & 5.28 & 2.77 & 25.36 & 14.17 & 2.11 & 1.14 & 0.35 & 19.38 & 9.49 & 53.38 \\
\hline 'Ao-10V' & 2.48 & 1.58 & 17.77 & 12.61 & 1.78 & 1.03 & 0.19 & 13.54 & 7.61 & 52.93 \\
\hline 'Ao-11V' & 3.22 & 1.82 & 22.08 & 12.43 & 2.63 & 1.37 & 0.25 & 18.08 & 8.18 & 53.42 \\
\hline 'Ao-12V' & 2.49 & 1.45 & 16.13 & 12.47 & 2.11 & 1.06 & 0.17 & 12.86 & 8.03 & 52.57 \\
\hline 'Ao-13V' & 3.10 & 1.87 & 19.40 & 13.44 & 2.18 & 1.12 & 0.24 & 14.94 & 8.65 & 52.32 \\
\hline 'Ao-14V' & 4.36 & 2.65 & 23.44 & 14.67 & 1.92 & 1.12 & 0.34 & 18.50 & 9.43 & 51.57 \\
\hline 'Ao-15V' & 3.76 & 2.03 & 19.96 & 13.83 & 2.14 & 1.11 & 0.27 & 15.34 & 8.98 & 51.66 \\
\hline 'Ao-1R' & 4.58 & 3.08 & 25.82 & 16.64 & 2.22 & 1.15 & 0.31 & 19.05 & 8.93 & 53.06 \\
\hline 'Ao-2R' & 3.89 & 2.17 & 20.94 & 13.83 & 2.54 & 1.27 & 0.26 & 16.22 & 8.40 & 51.81 \\
\hline 'Ao-3R' & 3.38 & 1.99 & 21.88 & 13.25 & 2.20 & 1.11 & 0.25 & 17.52 & 8.77 & 50.50 \\
\hline 'Ao-4R' & 3.42 & 2.17 & 20.63 & 13.82 & 2.40 & 1.06 & 0.25 & 15.63 & 8.20 & 53.90 \\
\hline 'Ao-5R' & 4.06 & 2.44 & 20.10 & 15.31 & 2.08 & 1.07 & 0.23 & 15.58 & 9.55 & 52.85 \\
\hline 'Ao-6R' & 3.65 & 2.27 & 20.59 & 13.73 & 2.43 & 1.17 & 0.24 & 15.43 & 8.18 & 52.76 \\
\hline 'Ao-7R' & 3.71 & 2.25 & 20.08 & 14.52 & 2.29 & 1.16 & 0.29 & 16.30 & 9.57 & 55.07 \\
\hline 'Ao-8R' & 3.56 & 2.19 & 21.22 & 13.34 & 2.77 & 1.16 & 0.32 & 17.73 & 8.59 & 52.45 \\
\hline 'Ao-9R' & 2.49 & 1.48 & 17.86 & 11.83 & 2.57 & 1.18 & 0.26 & 15.05 & 8.27 & 52.44 \\
\hline 'Ao-10R' & 5.61 & 3.38 & 24.26 & 16.32 & 2.29 & 1.04 & 0.23 & 18.05 & 9.05 & 51.77 \\
\hline 'Ao-11R' & 4.50 & 2.14 & 23.61 & 13.21 & 2.31 & 1.08 & 0.31 & 18.38 & 8.51 & 54.33 \\
\hline 'Ao-12R' & 3.09 & 1.92 & 20.22 & 13.56 & 2.07 & 1.15 & 0.29 & 16.01 & 8.91 & 56.22 \\
\hline 'Ao-13R' & 3.39 & 1.70 & 21.41 & 13.06 & 2.16 & 1.16 & 0.30 & 17.49 & 9.59 & 52.86 \\
\hline 'Ao-14R' & 4.06 & 2.29 & 24.31 & 13.80 & 2.27 & 1.30 & 0.39 & 18.93 & 9.11 & 52.47 \\
\hline 'Ao-15R' & 4.53 & 2.60 & 21.94 & 14.76 & 2.34 & 1.11 & 0.28 & 15.90 & 9.02 & 50.36 \\
\hline LSD at $5 \%$ & 0.009 & 0.004 & 0.02 & 0.02 & 0.002 & 0.001 & 0.06 & 0.01 & 0.001 & 0.82 \\
\hline
\end{tabular}

FW: Fruit weight, SW: Seed weight, SL: Seed length, Swi: Seed width, CN: Carpel number, AN: Almond number, AW: Almond weight, AL: Almond length, Awi: Almond width, OC: Oil content (\%)

corded in 'Ao-10V' (FW = $2.48 \mathrm{~g}$ ) and 'Ao-12V' (SW = $1.45 \mathrm{~g}$ ). 'Ao-12V' showed the lowest values for the almond weight. Seed length varied from $16.13 \mathrm{~mm}$ to $25.89 \mathrm{~mm}$ and almond length varied from $12.86 \mathrm{~mm}$ to $20.36 \mathrm{~mm}$. So, the highest seed and almond length was recorded in 'Ao-3V' and smalleast in 'Ao-12V'. Oil content expressed in percentage had a range of $50.36-56.22 \%$, with the lowest value in 'Ao-15R' genotype and the highest one in 'Ao12R'. Moreover, significant differences among genotypes were found for all traits studied.

\section{Variability and genetic parameter estimates}

The results of the analysis of variance, evaluation of mean and coefficient of variation over three years for the traits: fruit weight, seed weight, seed length, seed width, carpel number, almond number, almond weight, almond length,almond width and oil content are shown in Tab. 2. Significant variations among all the wild genotypes were found. A combined analysis of variance over three years indicated that year, genotype and genotypes $\mathrm{x}$ year interaction were highly significant $(p<0.01)$ for most of the tested characteristics.

The results showed a great phenotypic variation, mainly between genotypes, and revealed the existence of a potential for selection of genotypes under these environments.

Genotypic variance, phenotypic variance, genotypic and phenotypic coefficient of variation, heritability, genetic advance, and genetic advance in percent of mean for 10 different characters are presented in Tab. 3. The phenotypic variance and phenotypic coefficient of variation were higher than the genotypic variance or genotypic coefficient of variation for all the characters, suggesting the presence of environmental influence to some extent in the expression of these characters.

Higher values of genotypic and phenotypic variances were found for seed length, seed width, almond length, oil content. The highest phenotypic and genotypic coefficients of variation were found for the weight of fruit, seed and al- 
Tab. 2. Analysis of variance (GLM) of some characters for thirty argan trees studied during 2008 to 2010

\begin{tabular}{|c|c|c|c|c|c|c|c|c|c|c|c|}
\hline $\begin{array}{c}\text { Variation } \\
\text { sources }\end{array}$ & D.F & FW & SW & SL & SWi & $\mathrm{CN}$ & $\mathrm{AN}$ & AW & $\mathrm{AL}$ & AWi & OC \\
\hline Years & 2 & $320.67^{* *}$ & $152.01^{* *}$ & $6015.07^{* *}$ & $2.84^{* *}$ & $2.01^{* * *}$ & $9.66^{* *}$ & $2.67^{* *}$ & $4207.31^{* *}$ & $435.48^{*}$ & $36,44^{* * *}$ \\
\hline Genotype & 29 & $163.79^{* *}$ & $56.80^{* *}$ & $1493.06^{* *}$ & $28.24^{* *}$ & $12.61^{* * *}$ & $1.64^{* *}$ & $0.62^{* *}$ & $884.73^{* *}$ & $91.02^{* * *}$ & $10,41^{* * *}$ \\
\hline Genotype $\times$ years & 58 & $36.91^{* *}$ & $11.77^{* *}$ & $353.17^{* *}$ & $4.05^{* *}$ & $6.33^{* * *}$ & $0.65^{* *}$ & $0.23^{* *}$ & $353.02^{* *}$ & $54.06^{* * *}$ & $4,19^{*}$ \\
\hline Range over years & - & $2.48-5.61$ & $1.45-3.38$ & $16.13-25.89$ & $11.83-16.64$ & $1.78-2.77$ & $1.03-1.37$ & $0.17-0.39$ & $12.86-20.36$ & $7.61-9.80$ & $50.36-56.22$ \\
\hline Mean & - & 3.70 & 2.16 & 21.28 & 13.69 & 2.26 & 1.14 & 0.27 & 16.85 & 8.71 & 52.90 \\
\hline $\mathrm{CV} \%$ & - & 21.04 & 21.26 & 11.11 & 8.34 & 9.57 & 6.85 & 17.98 & 10.74 & 6.67 & 2.49 \\
\hline
\end{tabular}

Tab. 3. Estimates of genetic variables for fruit, seed and almond traits in argan tree

\begin{tabular}{|c|c|c|c|c|c|c|c|}
\hline \multirow{2}{*}{ Traits } & \multicolumn{2}{|c|}{ Variance } & \multicolumn{2}{|c|}{ Coefficient of variation (\%) } & \multirow{2}{*}{$\begin{array}{c}\text { Heritability } \\
(\%)\end{array}$} & \multirow{2}{*}{ Repeatability } & \multirow{2}{*}{$\begin{array}{c}\text { Genetic advance } \\
\text { as \% mean }\end{array}$} \\
\hline & Phenotypic & Genotypic & Phenotypic & Genotypic & & & \\
\hline Fruit weight & 1.26 & 0.75 & 29.70 & 22.91 & 59.52 & 0.76 & 0.94 \\
\hline Seed weight & 0.50 & 0.30 & 33.04 & 25.59 & 60.00 & 0.74 & 0.59 \\
\hline Seed length & 8.18 & 6.18 & 13.43 & 11.68 & 57.55 & 0.88 & 3.03 \\
\hline Seed width & 3.88 & 2.82 & 14.45 & 12.32 & 72.68 & 0.75 & 2.00 \\
\hline Carpel number & 0.26 & 0.11 & 22.46 & 14.61 & 42.30 & 0.47 & 0.30 \\
\hline Almond number & 0.12 & 0.01 & 30.93 & 8.93 & 8.33 & 0.10 & 0.04 \\
\hline Almond weight & 1.21 & 0.21 & 40.41 & 16.73 & 17.35 & 0.38 & 0.27 \\
\hline Almond length & 5.10 & 2.76 & 13.43 & 9.88 & 54.11 & 0.74 & 1.71 \\
\hline Almond width & 1.31 & 0.46 & 13.11 & 7.77 & 35.11 & 0.50 & 0.56 \\
\hline Oil content $(\%)$ & 3.34 & 3.27 & 3.48 & 3.44 & 97.90 & 0.62 & 2.50 \\
\hline
\end{tabular}

mond, indicating a higher degree of genetic variability for these characters. The phenotypic coefficient of variation was higher than the genotypic coefficient of variation for carpel number, almond number, almond weight, almond width, suggesting the presence of environmental influence in the expression of these characters. A higher heritability (broad sense) associated with high genetic advance in the fruit weight, seed weight, seed length, seed width, almond length and oil content (\%), suggested an additive genetic effect. The improvement of these characters would be effective for phenotypic selection.

\section{Genetic divergence analyses}

The genetic divergence among thirty argan genotypes was studied in order to know the extent of divergence in the genotypes, to identify the superior genotypes for utilization in improvement program and to find out the contribution of different characters towards genetic divergence in argan tree. The hierarchical clustering analy- sis technique performed on the thirty trees produced six groups (Tab. 4). Maximum number of genotypes (8 genotypes) was grouped in cluster VI. Cluster I consists of 6 genotypes followed by clusters II, III, IV, V with 4 genotypes for each cluster.

Inter and intra cluster distance $(D=\sqrt{ } D 2)$ values were worked out from divergence analysis and are presented in Fig. 3. The analysis showed homogeneity within groups with significant differences between mean values of traits from distinct groups.

Thus, the genotypes included within a cluster had less diversity among genotypes. The maximum intra-cluster distance was observed in cluster VI followed by cluster I, V, IV and III. The cluster II contained four genotypes and hence, its intra cluster distance was the lowest among the clusters. The highest inter cluster distance was observed between cluster VI and V, followed by clusters VI and III, VI and II, V and I, VI and IV and V and IV, suggesting more variability in genetic makeup of the genotypes

Tab. 4. Hierarchical clustering of argan tree based on measured agro-morphological traits

\begin{tabular}{ccc}
\hline Cluster number & Number of genotypes & Genotypes included in clusters \\
\hline I & 6 & 'Ao-2V' - Ao-7V' - 'Ao-11V' - 'Ao-3R' - 'Ao-8R' - 'Ao-13R' \\
II & 4 & 'Ao-6V' - 'Ao-13V' - 'Ao-4R' - 'Ao-6R' \\
III & 4 & 'Ao-4V' - 'Ao-8V' - 'Ao-7R' - 'Ao-12R' \\
IV & 4 & 'Ao-15V' - 'Ao-2R' - 'Ao-5R' - 'Ao-15R' \\
V & 4 & 'Ao-1V' - 'Ao-10V' - 'Ao-12V' - 'Ao-9R' \\
VI & 8 & 'Ao-3V' - 'Ao-5V' - 'Ao-9V' - 'Ao-14V' - 'Ao-1R' - 'Ao-10R' 'Ao-11R' - 'Ao-14R' \\
\hline
\end{tabular}




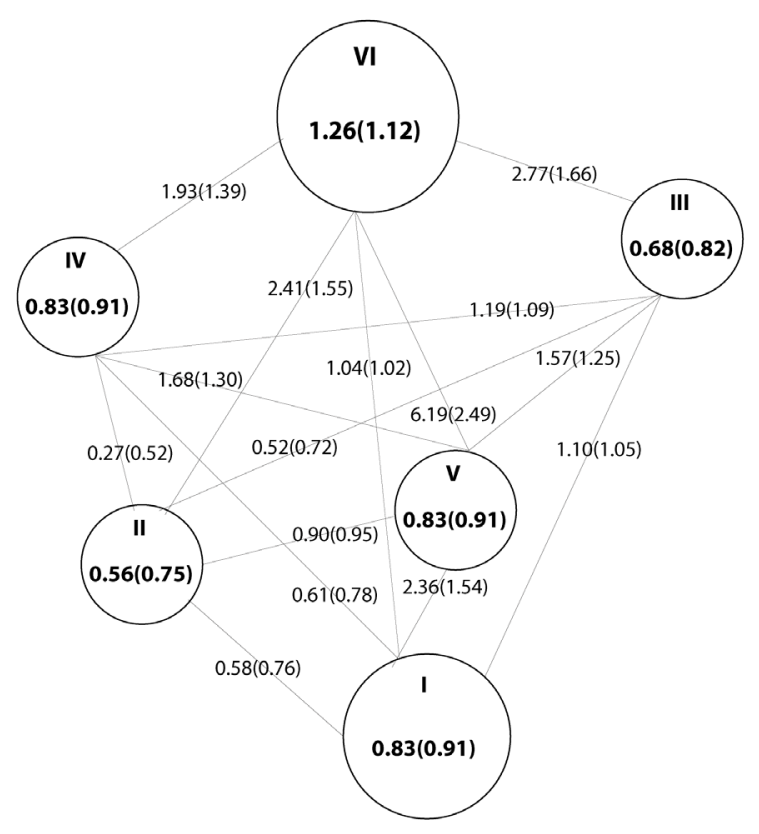

Fig. 3. Cluster divergences among six clusters of thirty genotypes of argan based on intra and inter distance

included in clusters $\mathrm{V}$ and VI. The intra cluster distance ranged from 0.56 to 1.26 . Cluster II showed minimum intra-cluster distance $(0.56)$ and maximum intra-cluster distance was exhibited by cluster VI (1.26) followed by cluster I, IV and V (0.83) (Fig. 3). Maximum inter cluster distance was found between clusters VI and V (6.19). Minimum inter-cluster distance was found to be minimum between clusters IV and II (0.27), suggesting a close relationship between them and a low degree of diversity among the genotypes.

Cluster means values of the ten characters are presented in Tab. 5. A perusal of results of cluster means revealed that cluster VI with eight genotypes exhibited the highest mean value for fruit weight (4.57), seed weight (2.63), seed length (24.34), seed width (14.57), almond weight (0.32),
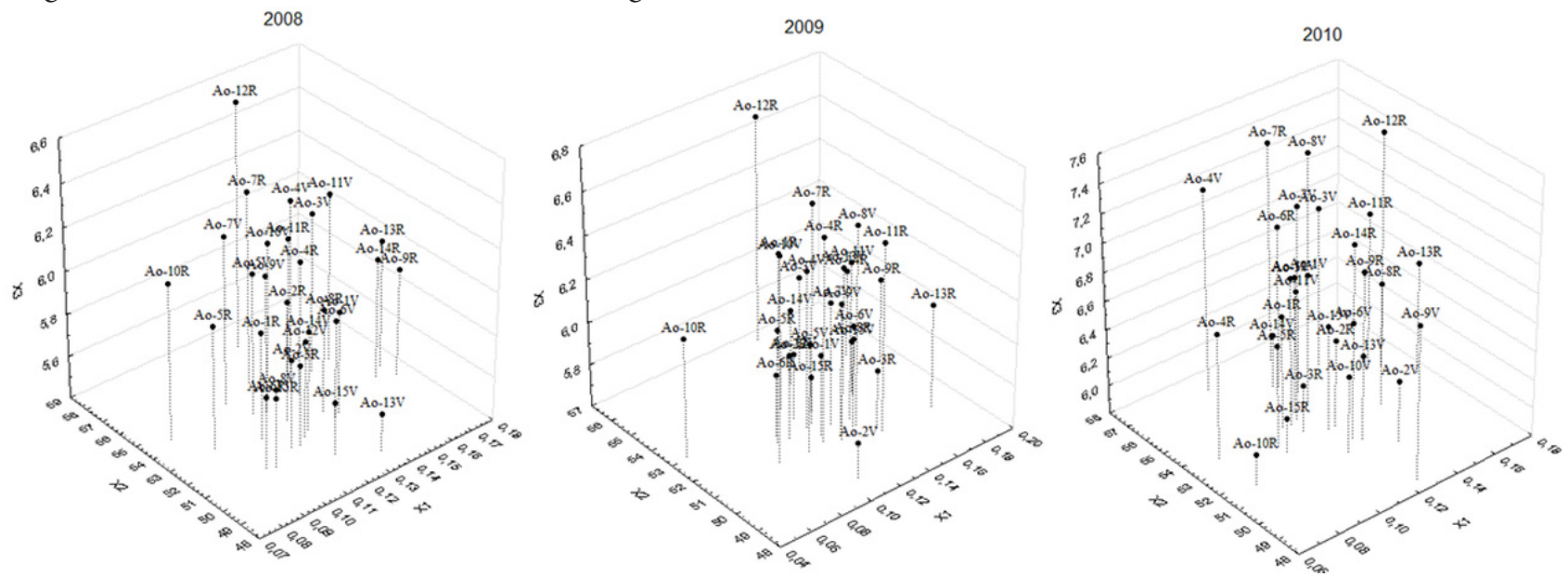

Fig. 4. Use of triplot analysis and hierarchical cluster analysis according to Ward method and generalized Euclidian distances for the investigation to identify the superior genotypes based on oil content data. Name of the genotypes are shown at the top of each bar for each years. The dendrogram grouping the genotypes selected and not selected based on the mean data for three years 
Tab. 5. Cluster means and percent contribution of different characters in thirty genotypes of Argan

\begin{tabular}{cccccccccccc}
\hline & FW & SW & SL & SWi & CN & AN & AW & AL & AWi & OC $(\%)$ & OV $(\mathrm{ml})$ \\
\hline Cluster I & 3.51 & 1.99 & 21.52 & 13.06 & 2.40 & 1.16 & 0.27 & 17.83 & 8.71 & 52.39 & 6.19 \\
Cluster II & 3.42 & 2.10 & 20.28 & 13.56 & 2.26 & 1.14 & 0.25 & 15.54 & 8.34 & 52.92 & 6.23 \\
Cluster III & 3.29 & 2.00 & 19.89 & 13.73 & 2.23 & 1.15 & 0.26 & 16.26 & 8.96 & 55.26 & 6.68 \\
\hline Cluster IV & 4.06 & 2.31 & 20.74 & 14.43 & 2.28 & 1.14 & 0.26 & 15.76 & 8.99 & 51.67 & 6.05 \\
Cluster V & 2.60 & 1.53 & 17.70 & 12.25 & 2.24 & 1.10 & 0.20 & 14.14 & 7.88 & 52.66 & 6.19 \\
\hline Cluster VI & 4.57 & 2.63 & 24.34 & 14.57 & 2.17 & 1.15 & 0.32 & 18.96 & 9.05 & 52.84 & 6.27 \\
\hline $\begin{array}{c}\text { Contribution of individual character } \\
\text { towards total genetic divergence (\%) }\end{array}$ & 6.35 & 6.64 & 6.02 & 7.65 & 10.84 & 12.15 & 6.69 & 6.72 & 4.93 & 16.02 & 15.99 \\
\hline
\end{tabular}

Genetic divergence existing in this studied population helps in the selection of suitable genotypes for utilization in breeding programs. Fig. 4 presented the genotypes selected in a collection of argan tree studied for three years (2008, 2009 and 2010).

The tri-dimensional triplot and dendrogram graphical method (Fig. 4) enabled the visual comparison of the genotypes studied and their interrelationships, and showed that the genotypes 'Ao-12R', 'Ao-7R', 'Ao-4R', 'Ao-4V', 'Ao$11 \mathrm{R}$ ', 'Ao-8V', and 'Ao-7V' appear to be the best in each considered year and could be good candidates in a future breeding program. Therefore, these genotypes considered for genetic improvement of oil yield was clustered through the hierarchical cluster analysis (Fig. 4).

\section{Discussion}

Evaluation program of various argan genotypes is essential to understand patterns of variability. The results showed a great variability of agro-morphological data, revealed the existence of a potential for selection and this quantification is important for tree improvement programs. Similar studies based on analysis of morphological characters have been carried out in the recent years (Ait Aabd et al., 2011; Bani Aameur and Ferradous, 2001; Zunzunegui et al., 2010). Therefore, the existence of variability in traits is essential for domestication purpose. Hence, in the similar studies, the domestication utilizes the variability within species to select trees with desirable traits (Atangana et al., 2002; Sanchez et al., 2011; Silva et al., 2009). This variability could offer some possibilities to identify the best genotypes. So, the agro-morphological characterization of plants is a common step in plant breeding for selection of parents and it also represents the first choice used for describing and classifying the germplasm (Gouwakinnou et al., 2011). Improvement of argan oil production might be an important criterion of selection during domestication process. Means of quality traits of the genotypes show that the highest value for oil content was recorded by genotypes: 'Ao-12R', 'Ao-7R', 'Ao-4R', 'Ao4V', 'Ao-11R', 'Ao-8V', and 'Ao-7V' which could be used as parental material for improvement of oil production. Oil content was an important contributor to the genetic divergence. Anuradha et al. (2004), Mohan and Seetharam (2005) and Loganathan et al. (2006) reported that oil con- tent was the main contributor towards genetic divergence in sunflower.

The results indicated that there was significant variation between genotypes the traits varied also significantly yearly. These variations can be attributed to genetic characteristics of trees and environmental conditions, similar to what has been reported in other studies (Abasse et al., 2011; Barracosa et al., 2007; Fandohan et al., 2011; Gouwakinnou et al., 2011; Sidina et al., 2009). Although, selection for morphological characters is a possible approach, an understanding of the inheritance of these characters, their genotype - environment interactions, and their correlation is needed to determine the validity of the breeding approach (Jenni and Hayes, 2010).

Multivariate analysis of genetic divergence among genotypes has resulted in the formation of six clusters and showed the existence of adequate genetic variation for further selection and breeding. Therefore, significant genetic distances between most clusters were observed from which selection of parents may be done. Parental material for improvement of argan oil production may be obtained from those genotypes which have high oil content in cluster III. Based on the results of this study, further restoration of argan genotypes selected from this population, through the assessment of genetic diversity should be practiced using progeny tests and cloning from mother plus tree, to test their adaptability under favorable and stress environments in diverse site conditions.

\section{Conclusions}

The study revealed considerable phenotypic diversity among the argan genotypes analyzed based on their agro-morphological characters, which varied significantly yearly, probably as a result of the different environmental conditions. Evaluation of this diversity with uni and multivariate analysis indicated the most performing genotypes for improvement programs.. Considering the overall results of the present study, argan trees from Aoulouz provenance evaluated in three years reveal a considerable range of diversity and a strong genotype and yearly interactions for several quantitative traits. Therefore, divergence analysis used to cluster the genotypes was an effective method in grouping these genotypes. It could be used to improve quantitative traits and thereby develop superior genotypes 
with desirable traits, and facilitate the management and utilization in trees improvement by selecting a workable collection. Higher heritability of oil content might be a key option for the improvement of these traits through selection. Hence, it was found to be important as the major contributor for genetic divergence. The genotypes included in clusters I and III are those suitable for selection for higher oil content. With divergence analysis we have shown that, it is possible to find genotypes with valuable morphological traits interesting for improvement programs. So, the genotypes 'Ao-12R', 'Ao-7R', 'Ao-4R', 'Ao-4V', 'Ao-11R', 'Ao-8V' and 'Ao-7V' are recommended for best oil production and could be better exploited for future domestication. The success of sampling strategies for ex-situ conservation and breeding is to test the stability and adaptability to different cultivation conditions using progeny and seed clone. This management approach appears to be recommended to help delineate future strategies for the conservation of this species, to capture genetic diversity existing in argan population and to assure high yield performance under different environments.

\section{Acknowledgements}

This work was carried out with financial support from the European Union and Social Development Agency of Morocco (Project no. APLARG no. 03_07) as well as the in kind support of the Association Agrotechnology for Souss Massa Draa. The authors express their sincere thanks for Association Agrotechnology for Souss Massa Draa, for Amehdar Mustapha and El Asbahani Abdelhafid for their technical assistance and rural women cooperatives for their help to choose the trees and the anonymous reviewers for specific comments.

\section{References}

Abasse T, Weber JC, Katkore B, Boureima M, Larwanou M, Kalinganire A (2011). Morphological variation in Balanites aegyptiaca fruits and seeds within and among parkland agroforests in eastern Niger. Agrofor Syst 81:57-66.

Ait Aabd N,El Ayadi F, Msanda F,ElMousadik A (2011).Evaluation of agro-morphological variability of Argan tree under different environmental conditions in Morocco: Implication for selection. Intern J Biodiv Conserv 3(3):73-82.

Anuradha N, Ramakumar PV, Vishnuvardhan Reddy A, Durga Rani CHV (2004). Genetic divergence in sunflower $(H$. annuus L.). The Andhra Agric J 51:39-43.

Assogbadjo AE, Kyndt T, Sinsin B, Gheysen G, Van Damme P (2006). Patterns of genetic and morphometric diversity in baobab (Adansonia digitata) populations across different climatic zones of Benin (West Africa). Ann Bot 97:819830.

Atangana AR, Ukafor V, Anegbeh P, Asaah E, Tchoundjeu Z, Fondoun JM, Ndoumbe M, Leakey RRB (2002). Domestication of Irvingia gabonensis. 2. The selection of multiple traits for potential cultivars from Cameroon and Nigeria. Agrofor Syst 55 (3):221-229.

Bani Aameur F, Ferradous A (2001). Fruits and stone variability in three argan (Argania spinosa (L.) Skeels) populations. Forest Genetics 8(1):39-45.

Barracosa P, Oso' Rio J. Cravador A (2007). Evaluation of fruit and seed diversity and characterization of carob (Ceratonia siliqua L.) cultivars in Algarve region. Sci Hortic114: 250257.

Charrouf Z, Guillaume D (1999). Ethnoeconomical, ethnomedical, and phytochemical study of Argania spinosa (L.) Skeels. J Ethnopharmacol 67:7-14.

Charrouf Z, Guillaume D (2002b). Chemistry of the secondary metabolites from Argania spinosa (L.) Skeels. Curr Topics in Phytochem 5:99-102

Divakara BN, Upadhyaya HD, Wani SP, Laxmipathi Gowda CL (2010). Biology and genetics improvement of Jatropha curcas L.: A review. Appl Energy 87:732-742.

Falconer DS, MacKay TFC (1996). Introduction to quantitative genetics, 4th edn. Longman, New York

Fandohan AB, Assogbadjo AE, Glèlè RL, Kyndt T, Sinsin B (2011). Quantitative morphological descriptors confirm traditionally classified morphotypes of Tamarindus indica L. fruits. Genetic Res Crop Evol 58:299-309.

Fox PN, Crossa J, Romagosa I (1997). Multi-environment testing and genotype environment interaction, 117-138 p. In: Kempton RA, Fox PN (Eds.). Methods for Plant Variety Evaluation. Chapman and Hall. London.

Gharby S, Harhar H, Guillaume D, Haddad A, Matthäus B, CharroufZ (2011). Oxidative stability of edible argan oil: A two-year study. LWT-Food Sci Technol 44:1-8.

Gouwakinnou GN, Assogbadjoa AE, Lykkeb AM, Sinsina B (2011). Phenotypic variations in fruits and selection potential in Sclerocarya birrea subsp. Birrea. Sci Hortic 129 (4): 777-783.

Jenni S, Hayes RJ (2010). Genetic variation, genotype $x$ environment interaction, and selection for tipburn resistance in lettuce in multi-environments. Euphytica 171:427-439.

Johnson HW, Robinson HF. Comstock RE (1955). Estimates of genetic and environmental variability in soybeans. Agron J 47:314-18.

Kaushik N, Kumar K, Kumar S, Roy S (2007). Genetic variability and divergence studies in seed traits and oil content of Jatropha (Jatropha curcas L.) accessions. Biomass Bioenerg 31(7):497-502.

Kaushik N, Kumar S, Kumar K, Beniwal RS, Kaushik N, Roy $S$ (2007). Genetic variability and association studies in pod and seed traits of Pongamia pinnata (L.) Pierre in Haryana, India. Genetic Res Crop Evol 54(8):1827-1832.

Khalil IA, Manan F (1990). Chemistry one. Bio-analytical chemistry, $2^{\text {nd }} E d, 53-55 \mathrm{p}$.

Leakey RRB, Fondoun JM, Atangana A, Tchoundjeu Z (2000). Quantitative descriptors of variation in the fruits and seeds 
316 of Irvingia gabonensis. Agrofor Syst 50:47-58.

Leakey RRB, Pate K, Lombard C (2005b). Domestication potential of marula (Sclerocarya birrea subsp. caffra) in South Africa and Namibia: 2. Phenotypic variation in nut and kernel traits. Agrofor Syst 64(1):37-49.

Loganathan P, Gopalan A, Manivannan N (2006). Genetic divergence in sunflower (Helianthus annuus L). Res on Crops 7:198-201

Lush JL (1940). Intra-sire correlation and regression of off-spring on dams as a method of estimating heritability of characters. Proc American Soc of Animal Prod 33: 293-301

Lybbert TJ, Aboudrare A, Chaloud D, Magnan N, Nash M (2011). Booming markets for Moroccan argan oil appear to benefit some rural households while threatening the endemic argan forest. PNAS 108 (34):13963-13968.

Maniee M, Kahrizi D, Mohammadi R (2009). Genetic variability of some morpho-physiological traits in durum wheat (Triticum turgidum var. Durum). J Appl Sci 9(7):13831387.

Mishra DK (2009). Selection of candidate plus phenotypes of Jatropha curcas L. using method of paired comparisons. Biomass and Bioenergy 33:542-545.

Mohan GS, Seetharam A (2005). Genetic divergence in lines of sunflower derived from inter-specific hybridization. SABRAO J Breed Genetics 37(2):77-84

Mudassar I, Amjad AM, Amjad A, Zulkiffal M, Zeeshan M, Sadaqat HA (2009). Genetic behavior and impact of various quantitative traits on oil contents in sunflower under waters stress conditions at productive phase. Plant Omics J 2(2):7077.

Nehdi IA, Sbihi H, Tan CP, Zarrouk H, Khalil MI, Al-Resayes SI (2012). Characteristics, composition and thermal stability of Acacia Senegal (L.) wild. seed oil. Industrial Crops and Produts 36:54-58.

Nerd A, Eteshola E, Boroway N, Misrahi Y (1994). Growth and oil production of argan in the desert of Israel. Industrial Crops and Products 2:89-95.

Nouaim R, Echairi A, Kaaya M, Chaussod R (2007). Contribution to the domestication of the argan oil production. Agricultures Cahiers 16(3):199-204.

Rahman MM, Al Munsur M (2009). Genetic divergence analysis of lime. J Bangladesh Agric Univ 7(1):33-37

Rao CR (1952). Advance statistical methods in biometric research. Ed. 1, John Wiley and Sons Inc. New York, 390 p.
Rao CR (1964). The use and interception of principal analysis in applied research. Sankhya 22:317-318

Rao GR, Korwar GR, Shanker AK, Ramakrishna YS (2008). Genetic associations, variability and diversity in seed characters, growth, reproductive phenology and yield in Jatropha curcas (L.) accessions. Trees 22:697-709.

Sanchez AC, Smedt SD, Haq N, Samson R (2011). Variation in baobab seedling morphology and its implication for selecting superior planting material. Sci Hortic 130:109-117.

Sidina M, El Hansali M, Wahid N, Ouatmane A, Boulli A, Haddioui A (2009). Fruit and seed diversity of domesticated carob (Ceratonia siliqua L.) in Morocco. Sci Hortic 123(1):110-116.

Silva JC, Borralho NMG, Araújo JA, Vaillancourt RE, Potts BM (2009). Genetic parameters for growth, wood density and pulp yield in Eucalyptus globules. Tree Genetics and Genomes 5:291-305.

Singh RK, Chaudhary BD (1977). Biometrical Methods in Quantitative Genetic Analysis. Kalyani Publishers, Ludhiana $191-200 \mathrm{p}$.

Toker C (1998). Estimate of heritabilities and genotype by environment interactions for 100-seed weight, days to flowering and plant height in kabuli chick-pears (Cicer arietinum L.). Turkish J Field Crops 3:16-20

Volker PW, Potts BM, Borralho NMG (2008). Genetic parameters of intra- and inter-specific hybrids of Eucalyptus globulus and E. nitens. Tree Genetics and Genomes 4:445460 .

White TL, Adams WT, Neale DB (2007). Forest Genetics. CAB International, Oxfordshire.

Yadav S, Suneja P, Hussain Z, Abraham Z, Mishra SK (2011). Genetic variability and divergence studies in seed and oil parameters of mahua (Madhuca longifolia Koenig) J.F. Macribide accessions. Biomass and Bioenergy 35:17731778.

Zobel B, Talbert J (1984). Applied forest tree improvement. New York John Wiley and Sons, 505 p. ISBN: 1930665814

Zunzunegui M, Ain-Lhout F, Jáuregui J, Díaz Barradas MC, Boutaleb S, Álvarez-Cansino L, Esquivias MP (2010). Fruit production under different environmental and management conditions of argan, Argania spinosa (L.). J Arid Environ 74:1138-1145. 